\title{
Upaya Peningkatan Hasil Belajar Siswa Melalui Model Pembelajaran Project Based Learning Dengan Berbantu Google Meet
}

\author{
Ismiyatin \\ SD Muhammadiyah Program Khusus Pracimantoro \\ ismiyatinqaishar@gmail.com
}

Article History

received 3/12/2020

revised $17 / 12 / 2020$

accepted $31 / 12 / 2020$

\begin{abstract}
The objective of this study was to improve student learning outcomes through the application of the Project Based Learning model. The type of research is classroom action research (CAR). The CAR model used was the C. Kemmis \& Mc Taggart spiral model which was carried out in 2 cycles. Data collection techniques are test techniques and non-test techniques. The research instrument using questions and observation sheets. The data analysis technique used is comparative descriptive. Based on the results of the study, it was shown that the cognitive domain of mathematics learning outcomes based on the percentage of completeness of precycle, first and second cycle learning outcomes was 40.7\%; 70.4\%; $88.9 \%$
\end{abstract}

Keywords: learning outcome,google meet, project based learning

\section{Abstrak}

Tujuan penelitian ini adalah meningkatkan Hasil belajar siswa ranah melalui penerapan model pembelajaran Project Based Learning. Jenis penelitian adalah penelitian tindakan kelas (PTK). Model PTK yang digunakan model spiral C. Kemmis \& Mc Taggart yang dilaksanakan dalam 2 siklus. Teknik pengumpulan data adalah teknik tes dan teknik non tes. Instrumen penelitian dengan menggunakan butir soal dan lembar observasi. Teknik analisis data yang digunakan adalah deskriptif komparatif. Berdasarkan hasil penelitian menunjukan bahwa hasil belajar matematika ranah kognitif berdasarkan persentase ketuntasan hasil belajar pra siklus, siklus I dan siklus II sebesar 40,7\%; 70,4\%; 88,9\%.

Kata kunci: hasil belajar, google meet, project based learning

Social, Humanities, and Education Studies (SHEs): Conference Series

p-ISSN 2620-9284 https://jurnal.uns.ac.id/shes e-ISSN 2620-9292 


\section{PENDAHULUAN}

Abad ke-21 disebut sebagai abad pengetahuan, abad ekonomi berbasis pengetahuan, abad teknologi informasi, globalisasi, revolusi industri 4.0, dansebagainya (I wayan, 2019).

Di abad ini banyak sekali perubahan yang sulit diprediksi. Tuntutan sumber daya manusia (SDA) di abad ini juga berubah. Dibutuhkan SDA yang terampil dan cakap agar bias mengikuti perkembangan zaman. Menurut Warger (dalam Siti, 2016), keterampilan yan harus dimiliki siswa untuk menghadabi perkembangan di zaman di abad 21 ini adalah: (1) kemampuan berpikir kritis dan pemecahan masalah, (2) kolaborasi dan kepemimpinan, (3) ketangkasan dan kemampuan beradaptasi, (4) inisiatif dan berjiwa entrepeneur, (5) mampu berkomunikasi efektif baik secara oral maupun tertulis, (6) mampu mengakses dan menganalisis informasi, dan (7) memiliki rasa ingin tahu dan imajinasi. Oleh karena pembelajaran di sekolah harus dirancar agar mampu mengembangkan keterampilan keterampilan tersebut agar siswa siap menghadapi tuntutan zaman

Berdasarkan hasil pengamatan terhadap hasil belajar mata pelajaran tematik siswa kelas 1 SD Muhammadiyah Program Khusus Pracimantoro tahun pelajaran 2019/2020 diketahui bahwa hasil belajar siswa kurang optimal, terutama pada muatan pelajaran Matematika. Dari 27 siswa di kelas nilai rata-rata ulangan harian siswa pada muatan matematika baru mencapai 58,9. Hasil studi do kumen daftar nilai siswa menunjukkan bahwa prosentase jumlah siswa yang mencapai ketuntasan belajar pada muatan matematika adalah 40,7 \%.Ditinjau dari proses belajar mengajar yang telah dilakukan, permasalahan di atas disebabkan karena kurangnya keterlibatan siswa dalam pembelajaran, metode pembelajaran yang dilakukan guru masih cenderung berpusat pada guru. Siswa mendapat konsep konsep materi hanya dari guru, tidak dengan menemukan konsepnya sendiri. Dalam pembelajaran siswa hanya pasif mendengarkan penjelasan materi dari guru. Selain itu, karena pembelajaran dilakukan secara daring dengan google meet maka pembelajaran kurang optimal. Kurang optimalnya pembelajaran tersebut dapat menyebabkan hasil belajar siswa juga kurang optimal.

Dari uraian diatas diketahui bahawa terdapat kesenjangan antara pembelajaran yang dilakukan di SD muhammadiyah program Khusus Pracimantoro dengan pembelajaran ideal di abad 21, sehingga perlu adanya perbaikan mutu pembelajaran melalui penerapan model yang dasar filosofinya konstruktivisme, yaitu siswa menemukan sendiri pengetahuannya sehingga siswa mampu memahami materi pembelajaran dengan bermakna sehingga hasil belajar siswa bisa lebih maksimal.

Menurut Von (dalam Akhiruddin, 2019) konstruktivisme merupakan salah satu filsafat pengetahuan yang menekankan bahwa pengetahuan kita adalah konstruksi (bentukan) kita sendiri. Pengetahuan dibentuk oleh struktur konsepsi seseorang sewaktu berinteraksi dengan lingkungan. Tujuan dari teori belajar ini adalah untuk menumbuhhkan motivasi peserta didik, mengembangkan motivasi dan kemampuan menjadi pemikir yang mandiri atau yang tidak harus distimulus terus. Konstruktivisme merupakan teori belajar yang mencoba menjelaskan bagaimana peserta didik belajar dengan membangun memahami untuk diri mereka sendiri.

Model pembelajaran Project Based Learning (PjBL) merupakan model pembelajaran berbasis konstruktivisme. Pendekatan pembelajaran berbasis proyek (PjBL) menciptakan lingkungan belajar "konstruktivis" dimana peserta didik membangun pengetahuan mereka sendiri dan pendidik menjadi fasilitator. (Goodman dan Stivers, 2010).

Menurut Dwi (2010) pembelajaran saat ini sebaiknyha bukan hanya pembelajaran aktif saya yang hanya menekankan pada kemampuan adapting tetapi lebih ke pembelajaran proaktif yaitu menekankan pada proses creating. Dengan 
pembelajaran berbasis proyek ini, siswa diarahkan agar mampu membuat (creating) suatu produk berdasarkan konsep yang diperolehnya dalam pembelajaran.

Menurut Wena (dalam Lestari, 2015: 14) menyatakan bahwa model Project Based Learning adalah model pembelajaran yang memberikan kesempatan kepada pendidik untuk mengelola pembelajaran dikelas dengan melibatkan kerja proyek. Kerja proyek merupakan suatu bentuk kerja yang memuat tugas-tugas kompleks berdasarkan kepada pertanyaan dan permasalahan yang sangat menantang dan menuntun peserta didik untuk merancang, memecahkan masalah, membuat keputusan, melakukan kegiatan investigasi, serta memberikan kesempatan peserta didik untuk bekerja secara mandiri. Dengan kegiatan tersebut siswa mampu mengkonstuk pengetahuannya sendiri.

Menurut The George Lucas Educational Foundation (dalam Aninda, 2019) mengemukakan pendapat bahwa langkah-langkah pembelajaran menggunakan Project Based Learning adalah sebagai berikut: 1) Dimulai dengan pertanyaan yang esensial, 2) Perencanaan aturan pengerjaan proyek, 3)Membuat jadwal aktivitas, 4)Memonitor perkembangan proyek peserta didik, 5) Penilaian hasil kerja peserta didik, 6) Evaluasi pengelaman belajar peserta didik.

Keunggulan penerapan model project based learning yaitu: (1) meningkatkan motivasi belajar peserta didik untuk belajar mendorong kemampuan mereka untuk melakukan pekerjaan penting, dan mereka perlu dihargai; (2) meningkatkan kemampuan pemecahan masalah; (3) membuat peserta didik menjadi lebih aktif dan berhasil memecahkan problem-problem yang kompleks; (4) meningkatkan kolaborasi: (5) mendorong peserta didik untuk mengembangkan dan mempraktikkan keterampilan komunikasi; (6) meningkatkan keterampilan peserta didik dalam mengelola sumber; (7) memberikan pengalaman kepada peserta didik pembelajaran dan praktik dalam mengorganisasi proyek dan membuat alokasi waktu dan sumber-sumber lain seperti perlengkapan untuk menyelesaikan tugas; (8) menyediakan pengalaman belajar yang melibatkan peserta didik secara kompleks dan dirancang berkembang sesuai dunia nyata; (9) melibatkan para peserta didik untuk belajar mengambil informasi dan menunjukkan pengetahuan yang dimiliki, kemudian diimplementasikan dengan dunia nyata; (10) membuat suasana belajar menjadi menyenangkan, sehingga peserta didik maupun pendidik menikmati proses pembelajaran" (Kurniasih dalam Nurfitriyani, 2016)

Dalam masa pandemi seperti sekarang ini, semua kegiatan yang dilakukan diluar rumah dibatasi. Surat Edaran (SE) yang dikeluarkan pemerintah pada 18 Maret 2020 segala kegiatan didalam dan diluar ruangan di semua sektor sementara waktu ditunda demi mengurangi penyebaran corona terutama pada bidang pendidikan. Pembelajaran dilakukan dari rumah secara daring/ jarak jauh. Menurut Isman (dalam Wahyu, 2020) pembelajaran daring merupakan pemanfaatan jaringan internet dalam proses pembelajaran. Salah satu platform yang bisa digunakan dalam pembelajaran daring adalah google meet. Melalui aplikasi google meet siswa dan guru dapat melakukan pertemuan secara tatap maya. Guru dapat berkomunikasi langsung dalam jaringan internet, guru dapat menampilkan materi pembelajaran dan juga dapat merekam kegiatan pembelajaran yang dilakukan. Kegiatan pembelajaran yang optimal diharapkan dapat meningkatkan hasil belajar siswa.

Hasil Belajar adalah suatu hasil yang diperoleh siswa setelah mengikuti proses pengajaran yang dilakukan oleh guru. Hasil belajar ini biasanya dinyatakan dalam bentuk huruf, angka, atau kata-kata baik. Menurut Wragg, hasil belajar ditandai dengan perubahan tingkah laku ke arah yang positif (Annurahman, 2012)

Tujuan dari penelitian ini adalah untuk meningkatkan hasil belajar siswa dengan penerapan model pembelajaran project based learning dengan berbantu google meet dalam pembelajaran tematik. 


\section{METODE}

Penelitian ini dilaksanakan di SD Muhammadiyah Program Khusus Pracimantoro kelas 1 semester 2 tahun pelajaran 2019/2020. Subyek penelitian adalah siswa kelas 1 SD Muhammadiyah Program Khusus Pracimantoro yang berjumlah 27 siswa. Jenis penelitian ini adalah penelitian tindakan kelas (PTK). Menurut Kemmis \& Taggart (dalam Mu'alimin, 2014) menyatakan bahwa prosedur PTK ini terdiri dari tiga tahapan yaitu perencanaan (planning), tindakan (action) dan obervasi (observe) dan refleksi (reflect). Penelitian ini dilakukan dalam dua siklus. Teknik pengumpulan data pada penelitian ini menggunakan teknik tes dengan memberikan butir soal yang berkaitan dengan mengurutkan berat benda denga satuan tidak baku. Teknik tes digunakan untuk memperoleh hasil belajar, sedangkan teknik non tes berupa lembar observasi berupa rubrik penilain pembelajaran digunakan untuk menilai aktifitas guru dan siswa selama pembelajaran. Teknik analisis data pada penelitian ini menggunakan teknik analisis deskriptif kualitatif. Teknik analisis mengacu pada model analisis Miles dan Huberman (dalam Hardani, 2020) yang terdiri dari tiga alur yaitu (1) reduksi data (data reduction); (2) penyajian data (data display); dan (3) penarikan simpulan..

\section{HASIL DAN PEMBAHASAN}

Penelitian ini dilakukan dalam dua siklus. Berdasarkan hasil penelitian dapat dilihat peningkatan hasil belajar siswa dari pra siklus, siklus I dan siklus II serta peningkatan aktivitas guru dan siswa pada tabel berikut:

Tabel 1. Data penelitian dalam setiap siklus

\begin{tabular}{llccc}
\hline \multirow{2}{*}{ No } & Kriteria penilaian & \multicolumn{3}{c}{ Muatan pelajaran Matematika } \\
\cline { 3 - 5 } & & Pra & Siklus 1 & Siklus 2 \\
& & 58,9 & 78,5 & 85,4 \\
1 & Nilai rata rata & $40,7 \%$ & $70,4 \%$ & $88,9 \%$ \\
2 & Kriteria ketuntasan & 71,3 & 78,8 & 86,3 \\
3 & Nilai observasi aktivitas siswa & & & \\
& & 72,5 & 82,5 & 87,5 \\
4 & Nilai observasi aktivitas guru & & & \\
\hline
\end{tabular}

Dari data pada table 1 diketahui bahwa terjadi peningkatan hasil belajar matematika setelah diterapkan model pembelajaran Project based learning. Penelitian ini dilakukan dalam 2 siklus, pada kegiatan pra siklus diketahui bahwa nila rata rata kelas adalah 58,9 jauh di bawaha nilai kriteria ketuntasan minimal (KKM) yang ditentukan sekolah yaitu 70. Jumlah siswa yang melampaui KKM 40,7\%. Setelah dilakukan penerapan model pembelajaran project based learning dengan berbantu google meet terjadi peningkatan hasil belajar matematika siswa, dilihat dari nilai rata rata matematika yaitu 78,5 dan ketuntasan siswa sebesar $70,4 \%$. Peningkatan hasil belajar matematika pada siklus 2 ini belum melampaui target peneliti yaitu $75 \%$ siswa menunjukkan ketuntasan pada hasil belajar matematika, sehingga siklus dilanjutkan dengan perlakuan yang sama yaitu penerapan model pembelajaran project based learning dengan berbantu google meet dalam pembelajaran. Pada siklus 2 menunjukkan peningkatan kembali yaitu nilai rata rata hasil belajar siswa meningkat menjadi 78,5 dan ketuntasan siswa mencapai $88,9 \%$.

Dari data diatas diketahui bahwa penerapan model pembelajaran project based learning dalam pembelajaran dapat meningkatkan hasil belajar siswa. Model pembelajaran Project Based Learning(PjBL) merupakan model pembelajaran berbasis konstruktivisme. Dalam pembelajaran siswa dituntut aktif, siswa diberikan proyek untuk diselesaikan, di dalam proyek memuat pertanyaan dan permasalahan yang sangat menantang dan menuntun peserta didik untuk merancang, memecahkan 
masalah, membuat keputusan, melakukan kegiatan investigasi, serta memberikan kesempatan peserta didik untuk bekerja secara mandiri . kegiatan ini dapat membantu siswa dalam pemahaman materi. Hal ini sesuai dengan penelitian yang dilakukan oleh Tin (2015) bahwa penerapan pendekatan konstruktivisme dalam pembelajaran dapat meningkatkan hasil belajar PPKn.

Dalam pembelajaran dengan menerapkan project based learning siswa meakukan kegiatan mengamati, menanya, mengkomunikasikan, sehingga siswa aktif dalam pembelajaran. Hal tersebut dapat dilihat pada hail observasi keaktifan siswa yang meningkat disetiap siklusnya, dari pra siklus, siklus 1 dan siklus 2 berturut turut $71,3,78,8$, dan 86,3 . Keaktifan siswa dalam pembelajaran ini dapat membantu siswa menambah pemahaman akan konsep yang sedang dipelajari sehingga hasil belajar dapat meningkat, hal ini sejalan dengan penelitian yang dilakukan oleh Astuti (2017) yaitu, keaktifan siswa berpengaruh positif terhadap hasil belajar IPA siswa kelas VII SMP Negeri 1 Turi tahun pelajaran 2016/2017.

Menurut Andita (2018) pembelajaran menggunakan Project Based Learning (PjBL) menjadi pengalaman bermakna karena memungkinkan siswa menguasai suatu konsep, memecahkan suatu masalah melalui penyelesaian proyek dan memberi kesempatan memunculkan ide-ide atau gagasan yang se-kreatif mungkin untuk menyelesaikan masalah tersebut. Kegiatan kreatif yang dilakukan siswa dapat meningkatkan hasil belajar. Hal ini sejalan dengan penelitian yang dilakukannya yaitu penerapan model pembelajaran project based learning ( $\mathrm{PjBL}$ ) dapat meningkatkan hasil belajar dan kreatifitas siswa kelas III sd negeri sidorejo lor 01 Salatiga.

Dalam penelitian ini selain penerapan model pembelajaran project based learning juga menggunakan platform google meet untuk membantu pelaksanaan pembelajaran daring. dalam pembelajaran dengan google meet ini siswa dapat melakukan pembelajaran dengan melakukan video conference bersama guru. Kegiatan ini dapat memberikan pengalaman baru bagi siswa dan menjadi solusi dari permaslaahan permasalahan yang terjadi dalam pembelajaran daring. termasuk rendahnya hasil belajar siswa. Hal ini sejalan dengan penelitian yang dilakukan oleh Siti (2020) yaitu hasil belajar siswa dengan menggunakan media aplikasi Google Meet lebih tinggi dibandingkan dengan hasil belajar siswa yang tidak menggunakan media aplikasi Google Meet.

\section{SIMPULAN}

Berdasarkan hasil penelitian dan pembahasan dapat disimpulkan bahwa penerapan model Project based learning berbantu google meet dapat meningkatkan hasil belajar matematika siswa kela 1 A semester 2 tahun pelajaran 2019/2020. Hal ini terlihat dari peningkatan hasil belajar matematika siswa dari setiap siklusnya dilihat dari nilai rata rata kelas dan kriteria ketuntasannya.

Berdasarkan hasil penelitian dan kesimpulan, maka disarankan kepada guru bahwa penerapan model Project Based Learning berbantu google meet dapat digunakan sebagai alternatif dalam pemecahan masalah pembelajaran pada siswa pada masa pandemic seperti sekarang ini. Penggunaan Project Based Learning juga dapat dikembangkan pada mata pelajaran atau pembelajaran tematik sebagai rujukan pada penelitian selanjutnya.

\section{DAFTAR PUSTAKA}

Akhiruddin., Sujarwo., Haryanto Atmowardoyo., Nurhikmah H. (2019). Belajar Dan Pembelajaran. Gowa: Cv. Cahaya Bintang Cemerlang 
Azizah, Aninda Nurul. (2019). Upaya Peningkatan Hasil Belajar Matematika Melalui Model Project Based Learning Siswa Kelas V SD. Jurnal Riset Teknologi dan Inovasi Pendidikan. Vol. 2 No. 1 (Januari) 2019, Hal. 194-204

Aunurrahman, 2012, Belajar dan Pembelajaran, Bandung:Alfabeta.

Dewi, Wahyu Aji Fatma. 2020. Dampak Covid-19 Terhadap Implementasi Pembelajaran Daring Di Sekolah Dasar. Jurnal IImu Pendidikan Volume 2 Nomor 1 April 2020 Halm 55-61

Goodman, Brandon and Stivers, J. 2010. Project-Based Learning. Educational Psychology. ESPY 505.

Hardani, dkk. 2020. Metode Penelitian Kuantitatif \& Kualitatif. Yogyakarta: CV. Pustaka IImu Group

Indrawati , Tin. (2015). Peningkan Hasil Belajar Siswa Dalam Pembelajaran Pendidikan Kewarganegaraan Dengan Menggunakan Pendekatan Konstruktivisme Di Kelas V Sekolah Dasar. Jurnal IImiah IImu PendidikanVolume XV No.1

Lestari, Tutik. (2015). Peningkatan Hasil Belajar Kompetensi Dasar Menyajikan Contoh Contoh Ilustrasi Dengan Model Pembelajaran Project Based Learning Dan Metode Pembelajaran Demonstrasi Bagi Siswa Kelas Xi Multimedia Smk Muhammadiyah Wonosari. Skripsi Tidak Dipublikasikan. Universitas Negeri Yogyakarta. Yogyakarta.

Muniroh, Siti Hilyatul. (2020). Efektivitas Pembelajaran Matematika Melalui Media Google Meet Ditinjau Dari Hasil Belajar Siswa Di Masa Pandemi Covid-19. Jurnal Edukasi dan SainsVolume 2, Nomor 2, Agustus2020;410419https://ejournal.stitpn.ac.id/index.php/edisi

Mualimin dan Cahyadi. 2014. Penelitian tindakan kelas (teori dan praktik). Ganding Pustaka. Yogyakarta

Redhana, I Wayan. (2019). Mengembangkan Keterampilan Abad Ke-21 Dalam Pembelajaran Kimia. Jurnal Inovasi Pendidikan Kimia, Vol 13, No 1, 2019, halaman $2239-2253$.

Suliswara, Dwi. 2010. Konsep Pembelajaran Project Based Learning. Semarang: Sindur Press

Surya, Andita Putri. (2018). Penerapan Model Pembelajaran Project Based Learning (Pjbl) Untuk Meningkatkan Hasil Belajar Dan Kreatifitas Siswa Kelas lii Sd Negeri Sidorejo Lor 01 Salatiga. Jurnal Pesona Dasar Vol. 6 No. 1, April 2018, Hal.41-54 Issn: 2337-9227

Wijayanti, Astuti. (2017). Pengaruh Media Video Pembelajaran Terhadap Hasil Belajar Ipa Ditinjau Dari Keaktifan Siswa. Jurnal LP3M - Universitas Sarjanawiyata Tamansiswa Yogyakarta - Vol.3, No.2, Agustus 2017

Zubaidah, Siti. (2016). Keterampilan Abad Ke-21: Keterampilan Yang Diajarkan Melalui Pembelajaran. Seminar Nasional Pendidikan, 2016 - researchgate.net 